\title{
VNIR-SWIR laboratory remote sensing investigation of carbonatites in various tectonic settings: Implications for critical metals
}

VERONIKA KOPAČKOVÁ ${ }^{1}$, VLADISLAV RAPPRICH ${ }^{2}$, TOMÁŠ MAGNA ${ }^{2}$, VIRGINIA MCLEMORE ${ }^{2}$, ONDŘEJ POUR $^{2}$

${ }^{1}$ Czech Geological Survey, Prague, Czech Republic; veronika.kopackova@geology.cz

${ }^{2}$ New Mexico Inst. Mining \& Technology, Socorro, USA

Modern methods of Remote Sensing (RS), such as mineral or imaging spectroscopy, became an innovative tool for detection and quantification of geological materials, monitoring of alteration processes and induced changes in physical/chemical properties. Therefore, RS represents an alternative to conventional methods (chemical-based assessment tools) and an efficient and cost-effective way not only to identify different minerals and/or chemical elements, but also model their abundances.

We investigated VNIR-SWIR spectra of natural samples of carbonatites from a range of settings (continental rift, intraplate post-trap, shear-zone), in contrast to experimental studies of synthetic REE-doped materials. To investigate whether proximal (laboratory) remote sensing allows quantitative prediction of bulk REE concentrations we further employed PLSR modelling. Using the VNIR-SWIR spectra, PLSR models were built for the sums of LREE (La-Gd) and HREE (Tb-Lu) as well as for the individual REE and compared with bulk-rock data acquired using conventional ICPMS analysis.

The preliminary results show that it may be possible to obtain reliable predictions for REE contents using VNIRSWIR analysis even when modelling the property of different carbonatite types. However, it also appears that postemplacement (hyrothermal) processes which the shear zone samples experienced, possibly caused mineral recrystallisation or changes in crystal lattices of the mineral group the REE are bounded with. In these cases, much better results were obtained when the samples were divided into two distinct groups achieving for bulk REE concentration $\mathrm{R}_{\mathrm{val}}{ }^{2}=$ 0.753 and $\mathrm{R}_{\mathrm{val}}{ }^{2}=0.792$ and for bulk HREE concentration $\mathrm{R}_{\text {val }}{ }^{2}=0.498$ and $\mathrm{R}_{\text {val }}{ }^{2}=0.571$. This phenomena and its relation to spectral property of REE carbonatites will be subject of further systematic study. Remote sensing in VNIRSWIR range can thus provide a cost-effective first-order estimate of concentrations of REE.

Supported by the Czech Science Foundation (19-29124X). 